\title{
The correlation of experimental results for condensation of steam from its mixture with air in channel of plate heat exchanger based on mathematical modelling
}

\author{
Petro Kapustenko ${ }^{1}$, Leonid Tovazhntanskyy ${ }^{1}$, Olga Arsenyeva ${ }^{1}$, Oleksandr Vasilenko ${ }^{1}$, \\ Sergiy Kusakov ${ }^{1}$ \\ 1. Integrated Technologies and Process ans Apparatuses Department, National Technical University Kharkiv \\ Polytecnical Institute, UKRAINE, Kharkiv 61002, E-mail: petro.kapustenko@kpi.kharkov.ua
}

\begin{abstract}
The process of steam condensation in the presence of air in channels of plate heat exchanger is investigated experimentall and with mathematical modelling. The equation accounting for transvers mass flux on heat and mass transfer is obtained. The results allow design of platecondenserss for steam containing noncodensable gas.
\end{abstract}

Keywords - heat transfer, mass transfer, condensarion, steam-gas mixture, mathematical model, experiment

A considerable amount of energy consumed in industry is lost as waste heat to the environment. The substantial quantities of this is latent heat of condensable vapours leaving out in the mixture of gases exhausting after burning of fuels, after processes of drying different materials and other exhaust gases from the industry. For efficient utilization of the heat in all such cases there is a need in effective heat transfer equipment which is capable to perform required duty in effective and economical way. Plate heat exchanger (PHE), as one of the modern efficient types of compact heat exchangers, is a good choice for this purpose. However the methods developed for their design with single phase flows [1] cannot be used in case of condensation in one of the heat exchanging streams.

The experiments for condensation of steam - air mixture in a sample of PHE channel were performed. The experimental model consisted of four plates welded together to form three inter plate channels. The channel parts on the gas - steam side were formed by combination of two pates with corrugation angle $\beta=60^{\circ}$. The saturated steam-air mixture was directed and condensed in the central channel. It was cooled by water flow in two periphery channels having thermally insulation on the outside. The temperature measuring points are situated at the inlet and exit of heat exchanging streams and at seven points along the channel. The pressure of gaseous stream is measured by pressure gauges at the inlet and exit of the channel. The mass flow rate of cooling water and the flow rate of incoming air are measured. The volumetric flow rate of water condensate created in channel was measured by set of measuring vessels and the flow rate of steam is determined by summing the water condensate flow rate with the flow rate of not condensed steam exiting channel and outgoing steam-air mixture at saturation conditions. The channel model is 1 meter long and its width is $0.225 \mathrm{~m}$. The corrugation height is $\mathrm{b}=5 \mathrm{~mm}$, thickness of the plate is $\delta=1 \mathrm{~mm}$, aspect ratio $\gamma=0.556$ and area increase coefficient $\mathrm{Fx}=1.15$. The experiments included 48 tests with different conditions of gaseous mixture condensation. The absolute pressure was changed in the range from 2.93 to 1.025 bar; the air volume fraction in entering channel mixture was in the range from $2.8 \%$ to $70 \%$; the local velocity of gaseous stream was in the range from 46 to $4.1 \mathrm{~m} / \mathrm{s}$; the temperature of gaseous stream changed in the range from 88.2 to $115.1{ }^{\circ} \mathrm{C}$; the temperature of cooling media varied from 23.8 to $71.5^{\circ} \mathrm{C}$.

To correlate the data of experiments with accounting for process local parameters distribution along the heat transfer surface the mathematical model of PHE for condensation of gas-vapor mixture is developed. The different available models for transvers mass flux influence 
on heat and mass transfer during condensation of steam from its mixture with noncondensable gas are checked by experimental data. As a base is taken analogy of momentum, heat and mass transfer discussed for PHE channels in paper [2]. The comparison with integral experimental results allowed to select the most reliable physical models of local processes. The model is implemented as software for PC. The estimation is made on the base of calculations of rootmean-square error for 62 experiments. The calculations with the model proposed for straight tubes in paper [3] have shown good accuracy at relatively small intensity of condensation process at volumetric concentrations of air in its incoming mixture with steam more than $50 \%$. The root-mean-square error of calculated outlet temperature of gas-steam mixture for these experiments was $1.8^{\circ} \mathrm{C}$. However smaller air content and high transverse mass fluxes the rootmean-square error is about $7^{\circ} \mathrm{C}$ with absolute error in some experiments up to $15^{\circ} \mathrm{C}$. It required the introduction of the additional parameters accounting for transverse mass flux proposed for the use in PHE channels in paper [4] for heat transfer $b_{H}$ and for mass transfer $b_{D}$ :

$$
b_{H}=\frac{c_{s}}{c_{m x}} \cdot \frac{J_{s}}{\rho_{m x} \cdot w_{m x} \cdot S t_{H}^{0}} ; b_{D}=\cdot \frac{J_{s}}{\rho_{m x} \cdot w_{m x} \cdot S t_{D}^{0}}
$$

where $J_{s}$ is steam flux to condensation surface, $\mathrm{kg} /\left(\mathrm{m}^{2} \cdot \mathrm{s}\right) ; w_{m x}$ is velocity of gas-steam mixture, $\mathrm{m} / \mathrm{s} ; c_{s}$ and $c_{m x}$ are specific heat capacities of steam and gas-steam mixture, $\mathrm{J} /(\mathrm{kg} \cdot \mathrm{K}) ; \mathrm{St}_{\mathrm{H}}{ }^{0}$ and $\mathrm{St}_{\mathrm{D}}{ }^{0}$ are heat transfer and mass transfer Stanton numbers calculated without the influence of transverse mass flux by heat and mass transfer analogy.

With introduction of parameters determined by Eq. (1) and adjusting coefficients with minimization of root-mean-square error the following correlations are obtained for heat transfer (H) and mass transfer ${ }_{(D)}$ Stanton numbers in conditions of transvers mass flux:

$$
S t_{H(D)}=S t_{H(D)}^{0} \cdot \ln \left(1+\frac{C_{s b}-C_{s f}}{1-C_{s f}}\right) \cdot\left(\frac{C_{s b}-C_{s f}}{1-C_{s f}}\right)^{-1} \cdot\left(1+1.9 \cdot b_{H(D)}\right)
$$

where $C_{s b}$ and $C_{s f}$ are mass fractions of steam at flow bulk and at condensate film surface.

The results of calculations with the developed model using Eq. (2) are compared with all experimental data. The root-mean-square error is $1.8{ }^{\circ} \mathrm{C}$ for outlet temperature of gas-steam mixture and $2 \%$ for total heat transfer load. It confirms the model validity and accuracy of Eq.

(2) acceptable for design of PHEs in industrial applications.

\section{References}

[1] O. P. Arsenyeva, L. L. Tovazhnyanskyy, P. O. Kapustenko, G. L. Khavin, "Mathematical modelling and optimal design of plate-and-frame heat exchangers." Chemical Engineering Transactions, vol. 18, pp. 791-796, 2009.

[2] P. Kapustenko, O. Arsenyeva, O. Dolgonosova, "The heat and momentum transfers relation in channels of plate heat exchangers," Chemical Engineering Transactions, vol. 25, pp. 357-362, 2011.

[3] M. Bucci, M. Sharabi, W. Ambrosini, N. Forgione, F. Oriolo, S. He, "Prediction of transpiration effects on heat and mass transfer by different turbulence models." Nuclear Engineering and Design. vol. 238, no. 4, Apr., pp. 958-974, 2008.

[4] L. L. Tovazhnyansky, P. O. Kapustenko, O. G. Nagorna, O. Y. Perevertaylenko, "The simulation of multicomponent mixtures condensation in plate condensers." Heat Transfer Engineering, vol. 25, no. 5, pp. 16-22, 2004. 